\title{
INTERFACE
}

Sociologias, Porto Alegre, ano 11, no 22, jul./dez. 2009, p. 314-351

\section{Eugenia e Fundação Rockefeller no Brasil: a saúde como proposta de regeneração nacional}

EISABEIEKOBAMSH*

INAFARIA*

MARIACONGEÇÃODACOSTA

\section{Resumo}

Nas primeiras décadas do século XX, a Fundação Rockefeller atuou de modo decisivo na implementação de ações voltadas para a saúde pública no Brasil, especialmente naquilo denominado de movimento sanitarista. Nesse mesmo período, a eugenia brasileira era equivalente ao sanitarismo, onde defendia-se a máxima de que "sanear era eugenizar". Vários trabalhos discutem o movimento sanitário, a questão da saúde pública no Brasil, a Fundação Rockefeller, a eugenia e seus ativistas. Entretanto, é escassa a discussão a respeito da Rockefeller e o movimento eugenista brasileiro. É necessário alertar que embora nos deparemos com questões ligadas à raça, teorias sobre genética ou evolução, este trabalho não tem como objetivo analisar tais assuntos com profundidade. 0 que buscamos construir foi o cenário no qual a eugenia de maneira geral, e a brasileira, especificamente, se desenrolou trazendo à tona as posturas de alguns eugenistas brasileiros.

Palavras-chave: Eugenia. Sanitarismo. Fundação Rockefeller. Cooperação internacional.

\footnotetext{
* Jornalista, D outoranda em H istória das Ciências e da Saúde da Casa de 0 swaldo Cruz (CO C Fiocruz), Mestre em Política Científica e Tecnológica (DPCT/Unicamp).

** Historiadora, Doutora em Saúde Coletiva (U erj), com Pós-doutorado em Política Científica e Tecnológica (Unicamp/Fapesp). Pesquisadora Associada ao Projeto Nacionalismo e Internacionalismo em Saúde IMS/U erj.

*** Professora Livre-D ocente do Departamento de Política Científica e Tecnológica da U niversidade Estadual de Campinas/Unicamp.
} 


\section{Introdução}

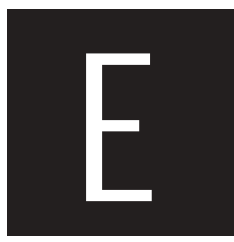

ste trabalho busca estabelecer uma conexão entre os movimentos sanitarista e eugenista, colocando em cena um ator importante para a sociologia da ciência brasileira, durante a primeira metade do século XX. Trata-se da Fundação Rockefeller, instituição norte-americana que escreveu, no plano internacional, um dos capítulos mais polêmicos da história da ajuda externa, da filantropia científica, ou do imperialismo econômicocultural, rótulos aplicados, alternativamente, conforme o recorte políticointerpretativo adotado pelo investigador. 0 presente trabalho busca escapar de fáceis rotulações, ao realçar as ambiguidades e efeitos não antecipados de todo esforço de cooperação internacional. A Fundação Rockefeller não poderia fugir a tais ambiguidades, frutos da política de negociações no campo das propostas e programas de saúde pública, no Brasil como em tantos outros países nos quais atuaram suas missões médicas e suas equipes de Enfermagem. A eugenia representou uma ideologia de "regeneração nacional" em um grande número de países; desde as primeiras décadas do Novecentos, frutificou no Brasil e aqui se aclimatou a partir de origens européias - foi em Londres e em outros centros europeus que frutificaram as primeiras associações e movimentos civis criados com propósitos eugênicos. Este trabalho contou com um levantamento bibliográfico minucioso, de modo a permitir observar o envolvimento da Fundação Rockefeller no movimento eugenista brasileiro ${ }^{1}$. N essa bibliografia, os trabalhos da brasilianista Nancy Stepan, historiadora e cientista política, for-

1 Um trabalho polêmico, que provocou uma primeira tentativa de discussão acadêmica no Brasil (ver KOBAYASHI, 2007), ganhou foros de verdade a partir do uso de documentos originais sobre o suposto papel da Rockefeller e da Carnegie no "movimento científico de limpeza étnica", que precedeu o apogeu das idéias nazistas em toda a Europa (BLACK, 2003). 
necem rico material sobre a eugenia, como movimento internacional e como proposta das elites brasileiras, de modo particular.

As questões ligadas à raça, especialmente o debate europeu, envolveram teorias so bre genética ou evolução, cujos proponentes principais, a exemplo do inglês Francis Galton, são brevemente discutidos neste trabalho. 0 pano de fundo europeu permite situar os desdobramentos do ideário eugenista no Brasil, no tocante à formação das correntes de pensamento e das políticas de saúde de cunho eugenista, adotadas ao longo das primeiras décadas do século XX. A leitura crítica do material coletado permite observar uma faceta singular do movimento eugenista brasileiro e também da própria atuação da Fundação Rockefeller. Se nos Estados U nidos e na Alemanha, a Rockefeller investiu diretamente em pesquisas e instituições ligadas à eugenia, aqui no Brasil se viu envolvida na trama de um movimento sanitário que já se alinhava no país, tendo à frente sanitaristas de projeção política como Carlos Chagas e Belisário Penna, articulados ao aparelhamento do Estado e, especificamente, à criação do Departamento Nacional de Saúde Pública (DNSP), em 1920. A análise da participação da Fundação Rockefeller no movimento eugenista brasileiro traz à tona diferentes vozes, algumas convergentes, outras divergentes, que aqui se pronunciaram. Nesse cenário, desenvolveu-se a eugenia com características próprias. Seus personagens mais marcantes situaram-se na interface de vários movimentos de salvação nacional, da saúde pública à educação, levando à dinâmica do movimento brasileiro elementos de complexidade e heterogeneidade, além de denominadores comuns em relação ao ideário e às propostas européias.

\section{A eugenia positiva de Francis Galton}

0 termo eugenia atribuído pelo estatístico inglês Francis Galton (18221911) ao movimento de melhoramento da raça humana, no final do século XIX, 
teria desdobramentos particulares e também desastrosos, como o extermínio dos judeus pelo nazismo alemão. Entretanto, vale frisar que da eugenia positiva de Galton ao advento do nazismo, em 1933, o movimento apresentou características peculiares de acordo com os países nos quais se desenrolou.

Inicialmente, Galton defendia a preservação da pureza de grupos particulares, por meio do casamento - ou se preferirmos - do cruzamento, entre os "melhores", que garantissem a geração de uma boa prole. Essa visão seria denominada como eugenia positiva (MACKENZIE, 1976). Entre os desdobramentos da eugenia positiva de Galton, destacam-se a eugenia preventiva e a negativa. A primeira integrava parte do programa social da eugenia que lidava com a erradicação dos "venenos raciais" (racial poisons) (STEPAN, 1991). A eugenia preventiva englobava a higiene da raça, preocupando-se com a puericultura, a educação sexual e a orientação pré-natal. Por sua vez, a eugenia negativa tinha como objetivo evitar a proliferação daqueles considerados "degenerados" (CASTAÑ EDA, 2003). Para os defensores da eugenia negativa era preciso desencorajar tanto a maternidade, como a paternidade dos "inaptos" (unfit) (MACKENZIE, 1976). Entre esses "três tipos" de eugenia, a negativa foi adotada em países como os Estados U nidos e a Alemanha. Em outros, como o Brasil, houve uma oscilação entre as três categorias, com predomínio da eugenia preventiva e positiva.

0 termo eugenia, emprestado do grego eugenés, por Francis J. Galton, para denominar o movimento de melhoria da raça, pode ser analisado de acordo com os seguintes aspectos: primeiramente, pela "origem" da palavra que significa bem-nascido. Como "movimento social", a eugenia representou a busca constante da sociedade pela melhoria da sua constituição, do encorajamento da reprodução dos indivíduos mais aptos e como "ciência", ofereceu um novo entendimento das leis da hereditariedade humana (STEPAN, 1991).

Conforme MacKenzie (1976), a eugenia de Galton associava-se muito mais à classe social à qual pertencia do que a qualquer tipo de obsessão 
por números ou medições, como alguns autores como Black (2003)² atribuem ao inglês. Ainda segundo M acKenzie (1976), Galton pode ser considerado como o "arquétipo da aristocracia intelectual" inglesa do século XIX. Bem-nascido, casou-se com alguém de uma família igualmente importante. Também estabeleceu conexões com a ciência, medicina, educação e a igreja. O s filhos do grupo social no qual havia nascido ocupariam na vida adulta posições importantes em universidades, escolas públicas, na ciência e na literatura.

\section{O utros atores envolvidos}

Galton não era o único a se ocupar com assuntos relacionados à raça, população ou ao crescimento populacional. Personagens como Thomas Malthus, Charles Darwin, Gregor Mendel, August Weissmann também se ocupavam dessas questões. 0 primeiro se voltava para assuntos ligados ao controle da procriação e da sua desproporcionalidade em relação à produção de alimentos, e, posteriormente, à defesa do controle dos matrimônios (CASTAÑEDA, 2003). Darwin, por sua vez, ofereceu a base científica para a defesa da seleção do casamento entre os melhores, ao alegar que a força e a fraqueza, o ajustamento e o desajustamento são qualidades que se herdavam (WELLS; HUXLEY; WELLS, 1941). As leis do frei Gregor Mendel, redescobertas em 1900, demonstrariam que a hereditariedade se ligava, exclusivamente, a fatores internos, que mais tarde se denominariam genes.

2 Edwin Black, em A guerra contra os fracos, narra a trajetória do movimento eugenista nos Estados Unidos e na Alemanha, buscando estabelecer uma correlação entre a atuação dos eugenistas em ambos os países e sua respectivas interações. Ao mesmo tempo, alega que a Fundação Rockefeller foi a maior incentivadora da eugenia durante a nazizmo alemão. 0 financiamento à biologia racial alemã tinha como objetivo, segundo o autor, averiguar "a composição específica do sangue dos incapazes - mesmo que isso significasse financiar instituições científicas controladas pelo nazismo" (2003, p.579). 
O alemão W eissmann estabeleceria a diferenciação entre o "somatoplasma" e o "germinoplasma". Enquanto as primeiras seriam responsáveis por carregar o material genético, as últimas serviriam como sustentação e nutrição para as células reprodutivas (STEPAN, 1991; CASTAÑEDA, 1998).

Galton morreu em 1911, mas a discussão que iniciou encontraria seu ápice na década de 1930, com o advento do nazismo na Alemanha. Stepan (1991) defende que em alguns casos é mais importante estudar a eugenia em suas formas não-nazistas, dada a excessiva brutalidade desta. Isso não significa defender um silenciamento em torno do período. Faz-se necessário abordar não somente o momento do advento do nazismo e as questões ligadas à eugenia, mas reavaliá-la como um movimento social e científico, levando em consideração, novamente, os atores envolvidos, 0 contexto da época, o papel desempenhado pelas fundações filantrópicas, como a Fundação Rockefeller e a Carnegie, por exemplo.

Sob a efervescência das décadas de 1910 e 1920: a institucionalização e a legitimação do movimento eugenista brasileiro

A criação da Sociedade Eugênica de São Paulo em 1918 representou o marco na institucionalização da eugenia no Brasil. A iniciativa, pioneira na América Latina, pode ser considerada vanguardista, já que a sociedade era apenas dez anos mais nova que sua correspondente inglesa e seis anos que a francesa. Além disso, a sociedade permitiu a sistematização de trabalhos ligados à eugenia produzidos no país. Seus interesses concentravam-se em questões relacionadas à legalização de exames pré-nupciais para prevenção e controle de doenças venéreas e campanha antialcóolicas. (CASTAÑ EDA, 1998). Falar sobre eugenia conferia modernidade ao meio científico e intelectual das primeiras décadas do século XX. M édicos, higie- 
nistas, juristas e educadores podem ser considerados os principais interessados nessa discussão e na idéia trazida no bojo do movimento de melhoria racial, mas também de "evolução, progresso e civilização: Em muitos casos, a eugenia era interpretada como a 'nova religião da humanidade', tamanho a admiração e a crença que os 'homens de ciência' depositavam neste saber científico" (SO UZA, 2006, p.19).

A escolha de São Paulo como cidade sede não foi um mero acaso. Capital de um estado estável economicamente, destacava-se também como importante força na política nacional. Apesar disso, não era objetivo de tal sociedade concentrar-se apenas no estado de São Paulo. Renato Kehl organizador e concomitantemente, secretário da Sociedade, convidara Belisário Penna para que atuasse como um dos três vice-presidentes honorários ${ }^{4}$. Respeitado, conhecido, especialista em saneamento, e carioca, Penna propiciaria a projeção da Sociedade para além das fronteiras paulistas (STEPAN, 2004). 0 médico e diretor da nova escola de medicina de São Paulo, Arnaldo Vieira de Carvalho ${ }^{5}$, foi nomeado presidente da Sociedade. Alguns membros de destaque: o bacteriologista e diretor do Instituto Butantã, Vital Brasil; o microbiologista, Artur N eiva (companheiro de Penna, na expedição aos sertões brasileiros); o médico e positivista, Luís Pereira Barreto; o educador, Fernando de Azevedo e o psiquiatra e professor da Faculdade de Medicina do Rio de Janeiro, Antonio Austregésilo.

Conforme Kehl (1923, p.165), a Sociedade Eugênica de São Paulo se propunha a estudar as leis da hereditariedade, concentrando-se em ques-

30 médico e eugenista Renato Kehl é considerado o principal representante e divulgador do movimento eugenista brasileiro e latino-americano entre o final dos anos 1910 até o início da década de 1930 (ver SO UZA, 2006).

4 Juntamente com Penna, também foram convidados os professores A. de Sousa Lima e Amâncio Carvalho.

5 Arnaldo Vieira de Carvalho, como veremos adiante, foi peça-chave na parceria estabelecida entre a Fundação Rockefeller e a U niversidade de São Paulo (USP), na criação da Faculdade de Medicina. A discussão completa acerca do assunto pode ser encontrada em Marinho (2001). 
tões da evolução e descendência, "tirando desses conhecimentos as bases aplicáveis à conservação e melhoria da espécie humana". As discussões, ainda segundo Kehl, bem como as questões debatidas pela sociedade, seriam aquelas "relativas à influência do meio, do estado econômico, da legislação, dos costumes, do valor das gerações sucessivas e sobre as aptidões físicas, intelectuais e morais, sempre tirando dessas discussões idéias destinadas a bem da nossa raça" (KEHL, 1923, p.165). Para ele, os três caminhos para regeneração racial eram a eugenia positiva, a negativa e a preventiva. No caso da eugenia preventiva, o ativista a considerava "a higiene profilática, a inimiga dos fatores hostis à humanidade: ela se bate pelo saneamento rural e urbano, luta pela supressão do álcool e de outros venenos intoxicantes, esforça-se pela regulamentação do trabalho, consiste enfim na prática da higiene em todos os seus artigos" (KEHL, 1923, p.201). Kehl considerava o saneamento como ponto de partida para que a eugenia se tornasse exequível. U ma prova cabível para aqueles que consideravam a eugenia e a regeneração da raça uma utopia (KEHL, 1923).

Apesar do entusiasmo e de contar com nomesilustres na sua composição, a Sociedade Eugênica de São Paulo sobreviveu apenas por um ano. A instituição não foi capaz de resistir à morte de Vieira de Carvalho em 1919 e à mudança de Kehl para o Rio de Janeiro (STEPAN, 2004). Entretanto, é importante salientar que, embora breve, a sociedade nesse tempo promoveu diversas reuniões, sessões regulares, nas quais discutiam-se os avanços na Europa no que se relacionava à eugenia, a necessidade do país se inserir nos estudos da hereditariedade, da evolução e da influência do meio ambiente, além de discutir também questões ligadas às condições econômicas, legais e de costumes e hábitos dos brasileiros (KEHL, 1929).

Estabelecido no Rio de Janeiro, Kehl não conseguiu organizar uma nova sociedade eugênica, mas, nem por isso, desistiu de propagar seus ideais. A eugenia defendida por ele encontraria espaço na nova Liga Bra- 
sileira de Hygiene Mental (LBHM) $)^{6}$, fundada em 1922, pelo diretor da Colônia de Psicopatas do Engenho de Dentro, Gustavo Riedel. A liga tinha como objetivos:

a) prevenir as doenças mentais a partir da observação dos princípios da higiene geral, enfatizando o sistema nervoso; b) proteger e amparar no meio social tanto os egressos como aqueles passíveis de internação; c) melhorar a assistência e tratamento aos doentes em asilos públicos, particulares ou mesmo fora deles e d) realizar um programa de Higiene Mental e Eugenia no domínio das atividades individual, escolar, profissional e social (REIS, 1994, p 50).

A LBHM surgiu como aliada nas aspirações do movimento sanitarista e eugênico de melhoramento do povo brasileiro. Para Riedel, a eugenia era uma antiga paixão, "a verdadeira religião da humanidade", por exprimir o aperfeiçoamento moral, físico e mental dos homens (REIS, 1994, p.54). O s psiquiatras brasileiros estavam convencidos de que por meio de ações voltadas para a defesa da saúde psíquica, contribuiriam na ampla tarefa de regeneração social. Os temas considerados importantes nessa empreitada eram semelhantes àqueles d efendidos pelos eugenistas, higienistas e médicos em geral: combate ao alcoolismo e aos "vícios sociais", imigração, seleção e orientação profissional, matrimônios, esterilização compulsória daqueles considerados degenerados, "atenção à infância para um desenvolvimento mental sadio e eugênico". O u seja: visavam o "meIhoramento da raça brasileira" (REIS, 1994, p.57). Até o final da década de 1920, a Liga defendia e seguia as mesmas orientações do movimento sanitarista, que considerava que o problema do país eram as doenças e a falta

6 Aqui é importante ressaltar que embora tenha se afiliado à LBHM , a história dessa instituição e a de Renato Kehl não devem ser avaliadas como um único objeto; havia muitas vozes concordantes e dissonantes na Liga (REIS, 1994). 
de educação. $\mathrm{N}$ a década seguinte, entretanto, a Liga passaria a defender uma postura mais radical em relação a medidas eugênicas. É importante salientar desde já, que a exemplo do movimento eugenista em geral, essa postura radical não era unânime na instituição. O utro ponto relaciona-se à presença do incansável Renato Kehl na instituição. N essa mesma época o ativista assume abertamente sua posição favorável a algumas medidas adotadas pelo movimento eugenista alemão, entretanto Reis alerta que a trajetória de Kehl não deve ser ligada diretamente às ações da LBHM.

Para os psiquiatras, a higiene mental e a eugenia possibilitariam prever o "nascimento de um novo tipo de homem, sadio, vigoroso, acima de qualquer suspeita", ou seja, livre de qualquer tara ou degenerescência (REIS, 1994, 40). Entre os membros da liga destacavam-se cientistas, médicos proeminentes da cidade. O bserve que figuravam nomes que, assim como Kehl, participavam do movimento eugenista brasileiro: o cientista e, na época, diretor do Instituto 0 swaldo Cruz, Carlos Chagas e o antropólogo e diretor do Museu Nacional do Rio de Janeiro Roquette-Pinto; 0 eugenista e ex-secretário da Sociedade Eugênica de São Paulo, Renato Kehl; o diretor do Hospital Nacional dos Alienados, Juliano Moreira; 0 presidente da Academia Nacional de Medicina, M iguel Couto; o professor de ginecologia e obstetrícia da Faculdade de M edicina do Rio de Janeiro, Fernando M agalhães; o higienista Afrânio Peixoto; o psiquiatra e professor da Faculdade de Medicina do Rio de Janeiro, Antonio Austregésilo e o especialista em doenças mentais, Henrique Roxo.

Conforme Reis (1994), o surgimento da Liga nesse período não foi um fato isolado: a LBHM é fundada no âmbito do que chamamos de a "efervescência da década de 1920". Basta observarmos a composição da instituição, e verificar que os membros de destaque eram basicamente os mesmos ativistas do movimento eugênico brasileiro e do movimento sanitarista.

Apesar da primeira medida de institucionalização da eugenia ter sido tomada em São Paulo, com a criação da Sociedade Eugênica daquele es- 
tado, realizou-se no Rio de Janeiro, em 1929, o Primeiro Congresso Brasileiro de Eugenia. Este testemunharia também a discussão entre as diversas teorias discutidas no país até aquele momento. As leis de Mendel, redescobertas em 1900, também seriam abordadas e defendidas por alguns eugenistas brasileiros. Das cinco lições do livro Eugenia: seus propósitos, suas bases, seus meios, O ctávio Domingues (1933) dedica uma lição inteiramente a Mendel. Intitulada Como Frei Gregório Mendel tornou-se imortal, a lição mostra como este, por meio de uma demonstração simples utilizando ervilhas, conseguiu comprovar a transmissão hereditária de alguns caracteres. Ao mesmo tempo, apesar do tom de crítica, conseguimos identificar, coexistindo com as leis do Frei, as idéias de Galton, no que se refere às medidas positivas e negativas em relação ao melhoramento da raça e do próprio Lamarck. Apesar de defender a impossibilidade de alteração da constituição genotípica do indivíduo, Domingues não despreza a importância da educação, das condições sociais e do próprio meio. 0 meio ambiente na caracterização do indivíduo era bastante significativo: "Bem grande. Enorme". Mas observava que no sentido lamarckiano, a influência do meio deveria ser negada, no que se referia a "sua ação (do meio) diretamente modificadora e modeladora das raças, das espécies" (DO MINGUES, 1933, p.110).

Para Domingues, a redescoberta das leis de Mendel permitiu que a eugenia se assentasse em leis biológicas, dando início "a construção de seu edifício científico em alicerces definitivos". 0 professor continua alegando que "as questões sobre a heredologia [leis biológicas] humana, somente com as leis de Mendel, tiveram soluções mais claras, plenamente aceitáveis" (DOM INGUES, 1933, 16). No artigo intitulado "O meio revela..."', Domingues defendia que, como o próprio título esclarece, o meio apenas revelava "as formas em potencial no genótipo dos seres, e nada mais. Alegava ainda que era necessário compreender o problema biológico com 
espírito inteligente e filosófico", sem superficialidades. Criticava o acúmulo de conhecimento em detrimento da compreensão (DO M INGUES, 1930,p. 1).

$\mathrm{N}$ a realidade, o professor do Departamento de Zootecnia se esforçava para esclarecer a confusão que, segundo ele, existia entre eugenia e eutecnia: "Já é tempo (...) de definir a Eugenia. E não é coisa fácil, em vista da confusão prejudicial que se processou em torno de duas coisas distintas" (D O MIN GUES, 1933, p.20). Domingues frisava que a eugenia se calcava exclusivamente nas leis biológicas, fornecidas pela genética, capazes de serem aplicadas à espécie humana. A eugenia, defendida na década de 1920, sinônimo de higiene, saneamento, se referia mais àquilo que denominou de eutecnia, ou medidas externas que agiam como estímulo, no desenvolvimento das heranças biológicas. Entretanto, ponderava, medidas "incapazes por si sós de mudar, de converter, de transformar tais heranças ou fatores genéticos, em suas qualidades intrínsecas, não podem, nem devem portanto ser incluídas na Eugenia" (DO M INGU ES, 1933, p.21). Domingues alegava que higiene, puericultura, saneamento e educação eram elementos independentes da eugenia: "Q uando se falar (...) em lei seca, em guerra aos entorpecentes, em higiene pré-natal, em reeducação de anormais, etc, etc, não se está absolutamente tratando de Eugenia" (DO M IN GUES, 1933, p. 21). Domingues reconhecia que tanto as medidas eugênicas, como as eutecnicas e até mesmo as sociais podiam ter como objetivo "a geração de proles boas em ambiente melhor", mas insistia que as "medidas puramente eugênicas" se relacionavam somente àquelas de ordem genética. Para o conjunto de ações dessas três áreas (eugenia, eutecnia e social), ele preferia o termo eugenismo, uma espécie de expressão guarda-chuva (DO MINGUES, 1933, p.23).

Roquette-Pinto possuía uma postura semelhante a de D omingues no que se relacionava ao domínio exclusivo da eugenia. Durante o Primeiro Congresso Brasileiro de Eugenia realizado em 1929, Roquette-Pinto em- 
preendeu uma campanha para tentar separar as ações de caráter estritamente eugênico, daquelas relacionadas à higiene, ao saneamento, ou à eutecnia. 0 antropólogo, a exemplo de Domingues, reconhecia a dificuldade de tal tarefa: "o conceito próprio daquela disciplina (eugenia) não está ainda muito claro no espírito de alguns, mesmo entre os melhores. Há pessoas, no Congresso, para quem 'Eugenia' é apenas um nome, em moda, de que se enfeita a velhíssima Higiene" (RO Q UETTE-PINTO, 1933,p.69). Roquette-Pinto alegava que o congresso relacionava-se a questões de ordem biológica, sem ter qualquer tipo de ligação com áreas como filosofia, religião, educação e pedagogia. Ele defendia que as preocupações da higiene eram bem diferentes das preocupações da eugenia. Enquanto a primeira buscava melhorar o meio e 0 indivíduo, a segunda procurava melhorar "a estirpe, a raça, a descendência". Conforme 0 antropólogo, a herança biológica era o "verdadeiro domínio da Eugenia" (RO Q U ETTE-PINTO, 1933, p.69-71). Na ata da sessão inaugural do Congresso, a diferenciação entre o que era pertencente à medicina e à higiene e aquilo que dizia respeito à eugenia já era explicitado:

Durante muito tempo, (...) supos-se que o meio dominava os organismos, portanto a medicina e a higiene resolveriam o problema da saúde; mas a ciência demonstrou haver alguma coisa que independe da higiene: é a semente, a herança, que depende da eugenia (Primeiro Congresso Brasileiro de Eugenia: Atas e Trabalhos, 1929, p. 11).

Por outro lado, alguns participantes do mesmo congresso ainda continuavam atrelados ao neolamarkismo. Numa das reuniões, por exemplo, reconhecia-se "o alto valor da educação moral como fator eugênico", e solicitava-se aos poderes públicos o desenvolvimento dessa educação nas escolas primárias e secundárias, conforme classificação da época (Primeiro Congresso Brasileiro de Eugenia: Atas e Trabalhos, 1929, p.14). Defendia-se ainda a luta antivenérea, o estímulo à educação física e aos exames 
pré-nupciais como medidas eugênicas, aspectos que para Roquette-Pinto em nada se relacionavam à eugenia.

Em conferência proferida nesse mesmo congresso, Kehl alegaria, diferentemente de sua postura inicial, que uma simples mudança de ambiente não seria capaz de regenerar um homem. Reconhecia a importância da educação no progresso social, masa esta somava o papel imprescindível do progresso biológico, da aplicação das leis da hereditariedade, conforme os preceitos eugênicos. 0 ativista alegava que a educação, as "injunções religiosas" eram insuficientes para "moderar as paixões, para tornar a humanidade melhor, mais equilibrada, mais filantrópica". O homem, para ele, estaria subjugado biologicamente à hereditariedade. Esta seria a responsável pelo seu temperamento e caráter de maneira "inexorável" (Primeiro Congresso Brasileiro de Eugenia: Atas e Trabalhos, 1929, p.47).

Ao observarmos as atas das reuniões do Congresso, nota-se o constante esforço para relacionar a eugenia exclusivamente às questões hereditárias. Entretanto, é possível encontrar assuntos ligados aos cuidados com o corpo, com a higiene ainda permeando essas discussões. Tanto que entre as muitas propostas e teses apresentadas e discutidas, algumas defendiam a necessidade de se criar cursos de higiene individual e sexual. O utras propunham a criação de um departamento nacional de Educação Física. O s congressistas defendiam também a instalação de cursos de eugenia em todas as escolas, mais especificamente nas faculdades de medicina; a exigência de exames pré-nupciais; a intensificação da propaganda antialcóolica, já realizada pela Liga Brasileira de Higiene M ental; a necessidade da divulgação das idéias eugenistas e a proteção à maternidade. A coexistência de assuntos ligad os exclusivamente a questões eugênicas, bem como a questões eutécnicas (emprestando a diferenciação estabelecida por 0 ctávio D omingues) mostra as diferentes posturas presentes no Congresso. Na ocasião houve discussões acirradas em relação à constituição 
racial, à imigração. O s assuntos abordados no congresso tentavam contemplar tudo o que se relacionava à eugenia, seja direta ou indiretamente.

\section{Eugenia, Saneamento e Fundação Rockefeller: uma outra face do movimento internacional}

O pensamento eugênico brasileiro se ligou intimamente ao movimento sanitarista iniciado no começo do século XX. A partir de meados de 1910, as políticas públicas de saúde se deslocaram dos centros urbanos para o interior do país. 0 saneamento do interior ou dos sertões começa a ser defendido como o estandarte da regeneração de um país que se encontrava assolado por doenças endêmicas. A missão Rockefeller chega ao país num momento em que a classe médica brasileira se inseria na discussão sobre a necessidade premente de sanear os sertões. Ao mesmo tempo, essa visão nacionalista e regenerativa permearia também o início das discussões do movimento eugenista brasileiro. Dada essa ligação, cabe nos questionar a respeito de que tipo de relação se estabeleceu entre eugenia, saneamento e a Fundação Rockefeller. À primeira vista parece não haver nenhuma conexão. Afinal, conforme as afirmações de Black (2003), o único intuito da instituição era financiar programas voltados supostamente para o extermínio daqueles considerados degenerados. N ovamente, contrariando tal pensamento, no Brasil, a Fundação Rockefeller desempenhou um papel fundamental na consolidação de um programa de saúde pública, voltada para o saneamento e para o combate de doenças como a ancilostomíase e a febre amarela (CASTRO SANTOS; FARIA, 2003). A Rockefeller chega ao Brasil não para exterminar os "degenerados" brasileiros, mas para instaurar programas sanitários que ajudassem na recuperação e na transformação do Jeca Tatu, de M onteiro Lobato, em "Jeca Bravo". O u seja, transformar uma população "infestada", segundo Kehl, de 
"raquíticos, pálidos, barrigudose papudos", num povo "valente". Segundo o ativista, a eugenia transformaria os homensem "protótipos da força, da robustez, e da resistência, - patenteando assim, aos olhos do mundo o nosso valor, e tornando-nos dignos do grande país - que é o Brasil" (KEH L, 1923,p. 203).

A distância entre as alegações de Black e as ações da Fundação Rockefeller no movimento eugenista torna-se ainda mais evidente ao se considerar que a eugenia no Brasil, na década de 1920, possuía características mais ligadas às medidas da eugenia preventiva, do que às da eugenia negativa. Nas duas primeiras décadas do século XX, o movimento eugenista brasileiro, como já abordamos, se ligava às questões sanitárias e de saúde pública.

No que se relaciona à atuação da Fundação Rockefeller na erradicação de enfermidades ${ }^{7}$ na América Latina, Palmer (2004, p.220) afirma que é inquestionável que "a saúde pública ao estilo Rockefeller mapeou e processou os povos do Terceiro Mundo em função da expansão imperial estadunidense". Ao mesmo tempo, Palmer alerta para o papel ativo dos países em que a Rockefeller atuou. Palmer (2004, p.220) salienta que ao se "considerar a experiência dos países anfitriões, surge toda uma série de novas perguntas e temas sobre os efeitos desses esforços em prol da saúde pública".

Cueto aponta que a Rockefeller associava o conceito de erradicação das doenças a enfermidades que julgavam "fáceis de identificar, tratar e controlar, com projetos que requeriam campanhas de curto prazo e de pouca inversão em infra-estrutura sanitária que pudessem modificar as condições ambientais e de vida" (CUETO, 1996, p 200)․ . Ao mesmo tem-

7 Cueto (1996) classifica o conceito de "erradicação das enfermidades" como algo ambicioso e controvertido. 0 autor alega que esses adjetivos também acabariam por caracterizar o tipo de relação que se estabeleceria entre os países latino-americanos e fundações filantrópicas internacionais, como a Fundação Rockefeller (FR), principalmente.

8 No período compreendido entre 1918-1940, a Rockefeller tentou erradicar da América Latina a ancilostomíase, a febre amarela e a malária, sucessivamente. Estas, por sua vez, foram colocando as ações da Fundação e o conceito de erradicação das enfermidades em xeque. Havia um duplo desafio: combater as doenças no seu aspecto biológico e ao mesmo tempo 
po em que critica essa postura da Fundação, Cueto afirma que a solução desses problemas estruturais era caríssima e não se encontrava na esfera de atuação da Rockefeller. Por outro lado, as ações da Rockefeller geraram efeitos colaterais como a reorganização das instituições de saúde pública locais, a extensão dos serviços sanitários às áreas rurais, além da substituição gradual do modelo acadêmico e técnico francês pelo norte-americano, que privilegiava o trabalho de pesquisa e a dedicação integral dos professores ao ensino. Tanto Cueto (1996) como Palmer (2004) destacam que a Fundação Rockefeller só estabelecia parcerias com países que solicitavam sua intervenção. Sem uma contrapartida do governo local, nada se efetivava.

Dessa forma, a relação entre a Rockefeller e o Brasil não se estabeleceu de uma maneira uniforme, ou totalmente harmoniosa, para nenhum dos lados. Primeiro: houve a necessidade de se negociar, e não apenas impor ações ao Brasil: "A interação entre brasileiros e norte-americanos não foi marcada pela hegemonia destes sobre aqueles, mas, antes, por um relacionamento entre iguais". As negociações foram marcadas por "elementos de confiança e desconfiança, de acomodação e de tensão, de convivência harmonioso e hostil" (CASTRO SANTO S; FARIA, 2003, p.10). As ações da Rockefeller por aqui não partiriam do zero, já que encontraria "uma tradição de pesquisa bacteriológica e uma tradição ' higienista' verdadeiras escolas formadas por $\mathrm{O}$ swaldo Cruz, no Rio, e por Emílio Ribas e Adolfo Lutz, em São Paulo". Diante disso, foi necessário um "ajuste" às tradições que precediam a vinda dos americanos ao Brasil (CASTRO SANTO S, 1985, p.15). Ao mesmo tempo, a Fundação Rockefeller, não deso-

lidar com as especificidades da América Latina. Cueto é bastante enfático ao enumerar os motivos pelos quais a campanha contra a ancilostomíase, por exemplo, fracassou: 1) a dimensão "gigantesca" da doença; 2) problema da quantificação segura das doses de remédios; 3 ) custo das campanhas; 4) "resistência de curandeiros e alguns médicos"; 5) construção de latrinas; 6) "tensões entre os experts estrangeiros e os inspetores locais"; 7) instabilidade política de alguns países (CUETO, 1996: 188). Tradução das autoras. 
bedecendo aos objetivos de sua própria constituição, institucionalizaria sua proposta pedagógica, no que se referia à maneira de se pensar a saúde pública como um espaço de pesquisa, e não apenas de clínica médica, como se praticava no país.

O contexto mundial acabou por fomentar a busca por um nacionalismo próprio. No perío do da Primeira Guerra M undial, o Brasil assistiu a geração de um novo nacionalismo. Enquanto na Europa se discutiam questões voltadas para a degeneração racial, aqui se defendia a necessidade de regeneração social (CASTRO SANTO S, 2004). No Brasil os sanitaristas defendiam a necessidade do despojamento da visão idílica do interior do país ao mesmo tempo em que criticavam a visão fatalista defendida por alguns, inspirada nas teses de inferioridade racial. Segundo Lima \& Hochman, "os intelectuais da campanha do saneamento rural aproximavam-se de uma tendência de crítica às teses de determinismo racial", essa inclinação devese ao fato da busca de uma identidade nacional trazida pela Primeira Guerra. Além de divulgar suas idéias, esses intelectuais "trouxeram para o debate dois novos elementos: a idéia da doença como característica central do povo e a qualificação do isolamento do sertanejo, indicado por Euclides da Cunha, como um estado de abandono da população do interior pelos governos" (LIMA; HOCHMAN, 1996, p.27). O alívio oferecido pelo movimento sanitarista residia na constatação de que o brasileiro era indolente, preguiçoso e improdutivo porque estava doente e abandonado pelas elites políticas. A redenção do país estava no saneamento de suas áreas rurais ou sertanejas. De acordo com o pensamento médico e intelectual da época era necessário melhorar as condições de vida da população (CASTRO SANTO S, 1985, 1989; LIMA \& HOCHMAN, 1996, p.23).

O prestígio das "ciências sanitárias" como estandartes do progresso brasileiro era fruto do sucesso de campanhas de saneamento contra a varíola, a peste bubônica e a febre amarela, sob o comando de 0 swaldo 
Cruz, entre 1902 e 1917. Isso serviu como estímulo ao crescimento de uma classe médica e profissional com orientações científicas cada vez mais delineadas e cada vez mais inseridas nas organizações federais e estaduais encarregadas da elaboração de políticas (STEPAN, 2004).

Em 1915, um ano antes da publicação do relatório Neiva/Penna, chegava ao Brasil a primeira comissão de especialistas da Fundação Rockefeller para avaliar as condições gerais de saúde pública e ensino médico na América Latina. Segundo o diretor da Junta Internacional de Saúde da Rockefeller, Wickliffe Rose, havia interesses em comum entre as duas "Américas", despertados pela Primeira Guerra. O Brasil, na visão de Rose, era um país estratégico e de importância fundamental na América do Sul, dadas suas proporções geográficas e a oportunidade que este oferecia de abrir fronteiras com os países vizinhos. Rose, em seu relatório, destaca também as conquistas brasileiras em medicina preventiva e o consentimento do governo brasileiro às atividades da missão. As comissões posteriores chegariam à região em 1916, com objetivos mais específicos e visavam identificar centros de ensino médico dispostos a implantar disciplinas de higiene e saúde, para capacitar profissionais atuantes em prevenção e campanhas de saúde pública. No caso do Brasil, a entidade escolhida foi a então recém-criada Faculdade de Medicina e Cirurgia de São Paul09. Para intermediar as negociações e formalizar o contato, a comissão recomendou o médico Arnaldo Vieira de Carvalho (MARIN H O, 2001). As áreas da saúde pública, que passariam a ser enfatizadas na faculdade, com o apoio da Fundação Rockefeller, eram convergentes com a ótica eugenista,

9 A raiz da Faculdade de Medicina e Cirurgia de São Paulo (FMCSP) foi fincada por meio do decreto n. 19, de 24 de novembro de 1891, "sancionado pelo presidente do estado, Américo Brasiliense, instituindo a Academia de Medicina, Cirurgia e Farmácia de São Paulo". Sua consolidação, entretanto, só ocorreu em 1912, pela promulgação da lei n. 1.357, de 19 de dezembro, quando passou a ser denominada como FM CSP. Em 1925, passou a Faculdade de Medicina de São Paulo e em 1934, Faculdade de Medicina da U niversidade de São Paulo (M ARINHO, 2001). 
de melhorar as condições da população brasileira. Vale lembrar que quando falamos em "melhoria", não há nessa frase uma conotação de que tanto o movimento eugenista como o sanitarista foram realizados democraticamente, ou em conjunto com as populações carentes. Ao contrário, as conquistas da reforma sanitária brasileira foram impostas, ao menos no que diz respeito ao seu período de formação, como tema típico de conquistas “'pelo alto', em que estavam em jogo percepções e valores de intelectuais, camadas médias e altas e a participação direta do Estado nacional" (CASTRO SANTOS, 2004, p.251).

Aludimos ao financiamento decisivo da Fundação Rockefeller à consolidação da pesquisa em ciências médicas no país. A medicina, até então, não podia ser considerada como uma área de pesquisa, mas simplesmente de clínica. 0 modelo proposto pela Fundação se calcava, em linhas gerais, na dedicação exclusiva dos professores, na redução do número de alunos e na criação de um hospital de clínicas anexo à faculdade. No caso deste trabalho, especificamente, é importante salientar que com a adoção desse modelo, de maneira indireta, a Fundação Rockefeller acabaria por fomentar também ideais de alguns eugenistas que acreditavam na higiene e na saúde pública como sinônimos de eugenia. Não somente disciplinas específicas a essas áreas foram implementadas no currículo do curso, como também foi criado um instituto de higiene, anexo à Faculdade de M edicina (CANDEIAS, 1984; FARIA, 1999; 2007; CAMPOS, 2002).

O s anos de 1920 podem ser considerados a época na qual a saúde pública seria considerada uma questão social para o país. Nesse mesmo período, as diretrizes da Fundação Rockefeller se associavam ao sanitarismo, ao considerar a enfermidade a origem da miséria (M ARINH O, 2001).

O presidente Epitácio Pessoa demonstrava uma preocupação constante com o progresso da saúde pública. Para ele a idéia do "progresso do país e o futuro da nacionalidade se atrelavam à melhoria de vida das po- 
pulações das zonas rurais, ao aperfeiçoamento da raça e ao desenvolvimento dasforças econômicas" (CASTRO SANTOS \& FARIA, 2003, p.31). Epitácio Pessoa criou o Departamento Nacional de Saúde Pública (DNSP) para unificar e ampliar os serviços de higiene federais e subordiná-los a uma direção única e autônoma. Kehl (1923, p.126) manifestaria sua satisfação ao alegar que "felizmente, começa-se pelo saneamento a praticar seriamente a eugenização da nossa terra". Para ele, a criação do DNSP seria o pontapé inicial de "uma vasta campanha de higienização nacional": "Sem esta iniciativa governamental, está visto, tudo o mais seria uma simples aragem de efeitos nulos". Kehl defendia que seria "a profilaxia das endemias e epidemias, trabalho básico de proteção sanitária", que concentrava "as esperanças cientificamente seguras do eugenismo" (KEHL, 1923, p. 126).

No governo de Artur Bernardes, foram implementadas ações decisivas em campanhas sanitárias no interior do país. No mesmo período, criouse a Sociedade Brasileira de Higiene, um "espaço de debates e discussões sobre as questões de higiene e saúde pública em âmbito nacional" (CASTRO SANTOS \& FARIA, 2003, p.33). O contexto político da década de 1920 era propício para que os acordos estabelecidos entre a Fundação Rockefeller e o país, que começaram a ser estabelecidos em $1915^{10}$, fossem consolidados definitivamente.

De fato, a década de 1920 foi um período fértil para a geração de ações de saúde pública. De 1 a 7 de outubro de 1923, realizou-se o Primeiro Congresso da Sociedade Brasileira de Higiene. Até o início da década de

10 Com o intuito de 'identificar áreas de atuação e coletar informações sobre as condições favoráveis ao combate de doenças infecciosas, como a malária, a ancilostomíase e a febre amarela', chega ao Brasil, especificamente em São Paulo, em 1915, a primeira comissão da Fundação Rockefeller, liderada pelo bacteriologista William Henry Welch e o então diretor do International Health Board, W ickliffe Rose. A conclusão a que a comissão chegou ao conhecer algumas regiões do país, foi semelhante à de Belisário Penna, em sua jornada no ano de 1913: a situação da saúde nas regiões rurais era calamitosa. 
1930, foram realizados mais quatro congressos. A partir do segundo, os congressistas passaram a discutir aspectos da ética profissional, patriotismo da ação higienista, seu caráter técnico de intervir na sociedade e seu significado para o melhoramento da raça. U m dos mais destacados congressistas, Amaury Medeiros, reafirmava a crença na "função essencial" que desempenharia a educação higiênica "na formação eugênica da raça" (CASTRO SANTOS; FARIA, 2003, p.34). A tônica dos congressos residia nas questões relativas aos problemas da urbanização e industrialização. Essa mudança de ênfase, das áreas rurais para as urbanas, marcaria a década de 1930.

\section{Afinal, qual era a constituição do povo brasileiro?}

A situação racial do país resultava da fusão de indígenas, africanos e povos europeus. Desde a transferência da Coroa portuguesa em 1808, raça e relações raciais se tornariam centrais nas discussões acerca da realidade social e dos debates ideológicos sobre a capacidade brasileira e 0 destino nacional. Nessa arena, a ciência se tornou um instrumento de autoridade cada vez maior para interpretações sociais e - especialmente raciais (STEPAN, 2004). Esse hibridismo também foi destacado pelo diretor da Junta Internacional de Saúde da Fundação Rockefeller, W ickiliffe Rose, no relatório enviado à fundação com suas avaliações a respeito do Brasil $^{11}$. Rose descreve o país como sendo multirracial. Destaca as qualidades dos imigrantes e de alguns nativos brasileiros que haviam se misturado aos primeiros, provendo o país de uma prole resistente, apesar dos negros e de uma parcela de portugueses tidos como indolentes.

Apesar de possuir características próprias, a ciência brasileira como um todo absorveu alguns aspectos das discussões internacionais. Com as

11 Ver Faria, 1995. Comentário sobre o documento do Rockefeller Archive Center, 'Public Health Situation and Work of the International Health Board in Brazil, by Wickliffe Rose, General Director'. 
questões ligadas à raça não foi diferente. A visão racista vinda do exterior era compartilhada por alguns brasileiros. A miséria e falta de saúde da população trabalhadora relacionavam-se, em sua maioria, à população negra e mulata. Último país do hemisfério a abolir a escravidão, o Brasil abandonou os ex-escravos à própria sorte, sem educação ou recompensa. Num cenário de rápidas mudanças sociais e econômicas, estes se uniam às correntes migratórias de pobres sem profissão e fugiam para as cidades. Lá, competiam, em condições desiguais com a leva de imigrantes, contabilizada em um milhão e meio, que chegara ao país entre os anos de 1890 e 1920 (STEPAN, 2004).

Na década de 1920, a eugenia preventiva dominou o cenário, mantendo latentes as discussões acerca de raça. $\mathrm{Na}$ esfera pública, as discussões giravam em torno de um discurso "assimilacionista", em contraposição àquilo que acontecia na esfera privada, um discurso social e racialmente discriminador. A ênfase na ligação da eugenia com o saneamento e saúde pública, nessa época, não deixou de ser um subterfúgio para a conquista da opinião pública, a respeito da necessidade de se aprimorar o povo brasileiro, bem como para "driblar" uma sociedade extremamente conservadora, católica. Em relação a questões sobre reprodução, a postura da classe médica não era diferente. Havia uma oposição generalizada à esterilização eugênica, independentemente de quaisquer motivos defendidos. De maneira geral, o otimismo permeou as discussões eugênicas no período. Isso não significou, porém, que assuntos como aborto, controle de natalidade e esterilização fossem discutidos como medidas para controlar a reprodução de indivíduos considerados inadequados. O s exames prénupciais, tão defendidos na época, representariam uma maneira sutil de se tentar selecionar os pares mais aptos, ou para proteger os nubentes de um par infectado por alguma doença. Essa preocupação redescobriu uma puericultura antes do nascimento. Dessa maneira, puericultura e eugenia 
se ligavam, intimamente, ao defender os cuidados com a saúde da mãe e da criança, como formas de preservação dos bem-nascidos. Além disso, a preocupação com a natalidade pode ser vista como um fator econômico. Basta lembrar, novamente, o relatório da Rockefeller, ao destacar a riqueza potencial de áreas ainda pouco exploradas e desabitadas, como era o caso do Planalto Central. O neomalthusianismo era denominado, aqui, como maternidade consciente. A idéia de progresso e crescimento se atrelava à imagem de um país densamente povoado. Povoado, entretanto, pela melhor estirpe. 0 saneamento, nesse contexto, "era visto como uma forma de 'investimento' no sentido político-econômico tradicional, com o objetivo de criar uma força de trabalho saudável e evitar uma revolução social provocada pela miséria" (STEPAN, 2004, p. 353).

0 quesito 'pró-natalidade' pode ser considerado mais uma peculiaridade do movimento eugenista brasileiro. Não havia uma defesa de uma esterilização, segregação ou eliminação dos doentes, mas uma idéia de que o país era um "vasto hospital", que exigia um programa de saneamento para a erradicação das doenças que o assolavam. Estas, por sua vez, eram consideradas prevalentes entre os pobres, ou entre a população principalmente negra e mestiça: "Essa população era percebida como ignorante, doente e cheia de vícios, com altas taxas de alcoolismo, imoralidade, mortalidade e morbidade" (STEPAN, 2004, p.356). Publicamente, a literatura eugênica utilizava o termo "raça" de maneira genérica, quando na realidade, o termo era específico para designar a "raça negra". É importante frisar que, embora possuísse um caráter racista, a eugenia brasileira na década de 1920, não defendia uma higienização ao estilo de Hitler, defendendo a esterilização ou eliminação de qualquer raça. M esmo porque, muitos membros da elite não tinham certeza da "pureza" de seu próprio sangue (STEPAN, 2004).

Nesse período, o Brasil estava em busca de uma reinterpretação de sua nacionalidade. Esforçava-se para resgatar o país da acusação de deca- 
dência tropical e degeneração racial. Muitos higienistas negavam que o ambiente do país fosse hostil a alguma raça, sendo capaz de adoecê-la. 0 calor dos trópicos, na visão européia, era responsável pela incapacidade do branco prosperar e trabalhar e pela degeneração dos brasileiros. O s brasileiros viam nas novas ciências da bacteriologia e microbiologia, maneiras de tratar diretamente da questão da "degeneração tropical". Nesse contexto, a higiene pública e as ciências do saneamento eram sinônimos de um futuro promissor para o país: "A identificação da eugenia com saneamento foi uma das conseqüências da importância dada à 'saúde' tropical na década de 1920" (STEPAN, 2004, p.357).

$\mathrm{N}$ a década de 1920, enquanto os Estados U nidos e a Alemanha se esforçavam em desenvolver uma raça pura, os cientistas brasileiros se esforçavam para se livrar da acusação de "degenerescência mulata: A avaliação negativa dos mulatos pelos cientistas europeus e norte-americanos era confrontada pela afirmação brasileira de que seria por meio da miscigenação racial que o Brasil realizaria seu próprio futuro 'eugênico' "(STEPAN, 2004, p.357). Roquette-Pinto (1933) defendia que, se os mestiços estavam "desaparecendo", não era devido à sua constituição, mas às condições sociais precárias a que estavam submetidos. Alegava que, do ponto de vista intelectual, os mestiços não eram inferiores aos brancos. 0 tal "racismo sutil" pode ser verificado nas palavras de Roquette-Pinto (1933, 150) ao fazer a seguinte ressalva em relação aos mestiços: "É verdade que eles não são tão profundos, embora sejam às vezes, mais brilhantes". Entretanto, logo salienta que tal postura tratava-se mais de um traço cultural dos povos latinos. $\mathrm{Na}$ sua defesa de tese continuava a alegar que "os mestiços que recebem instrução técnica (mecânicos, operários especializados, etc.), são tão bons quanto os europeus". Roquette-Pinto atribui a degradação dos mestiços das grandes cidades, à corrupção do "meio cosmopolita" naqueles que a educação não fortificara. Classifica o "mestiço opilado" do 
interior como perseverante, firme, dedicado. Novamente alerta que do "ponto de vista moral, no entanto, é preciso reconhecer que os mestiços manifestam uma acentuada fraqueza: a emotividade exagerada, ótima condição para o surto dos estados passionais" (RO Q U ETTE-PINTO, 1933, p.150). Domingues considerava o mestiço um produto de hibridização mendeliana normal e saudável, e o Brasil um exemplo "especial e precioso" de miscigenação racial. Para D omingues, se se pudesse atribuir alguma inferioridade ao mestiço, esta não era maior do que as raças consideradas puras na Europa. De acordo com esse mendeliano, a miscigenação não poderia ser considerada a causa da degeneração racial, masum "processo biologicamente adaptativo que permitiria" o desenvolvimento de civilização verdadeiramente tropical (STEPAN, 2004, p.369). A superioridade do branco e sua impossibilidade de se adaptar aos trópicos são colocadas em xeque por Roquette-Pinto, ao alegar que a nacionalização do imigrante era considerada um paradoxo:

Quando o "estrangeiro" era colocado junto ao 'homem rústico' nacionaliza-se depressa, mas adquire os mesmos hábitos deste. Por sua vez, quando isolado em boas condições de meio, começa a produzir progresso, mas não se nacionaliza na mesma velocidade do primeiro (RO Q UETTE-PINTO, 1933, p.124).

O utros, como Renato Kehl, consideravam a miscigenação um risco para o crescimento do país. No livro Lições de Eugenia (1929), Kehl considerava o desaparecimento dos índios e negros como uma prova da superioridade da raça branca, que permaneceria. O s mestiços eram considerados inferiores. Kehl era contrário ao fomento da imigração negra e amarela. Havia um desejo de se homogeneizar o país. Para ele, era um desperdício de tempo permitir que tais povos aportassem no Brasil, já que estavam fadados ao desaparecimento. Em relação ao cruzamento de raças, ele alegava tratar-se de um "elemento perturbador da evolução natural" e que não constituía meio de aperfeiçoamento étnico. Kehl defendia que aque- 
les que acreditavam no contrário o faziam sem fundamento científico. Do ponto de vista eugênico, ele contraindicava "toda e qualquer união de raça, isto é, entre indivíduos da raça branca com a negra, da branca com a selvagem, da branca com a amarela, e assim por diante" (KEH L, 1929, p.191). A questão da miscigenação dividia as opiniões. Era quase impossível chegar a um consenso. Durante as discussões acerca do assunto no Primeiro Congresso Brasileiro de Eugenia, essa contenda se evidenciou ainda mais.

No congresso os trabalhos eram apresentados e suas conclusões discutidas entre os participantes. Esse era o momento no qual as vozes, na maioria das vezes, discordavam. Em relação à miscigenação alguns, como O scar Fontenelle eram categóricos ao afirmar que "o cruzamento de raças diversas é mau" e alerta a respeito do perigo da imigração negra e japonesa. Já outros como Fernando Magalhães defendiam que a eugenia não excluía a humanidade. Para ele, não eram os "pigmentos" que determinavam as qualidades das raças: "As restrições impostas às correntes imigratórias importam numa injustiça e num suicídio. (...) Há uma injustiça, porque todo nosso passado se funda no mestiço e há um suicídio, porque todos somos mestiços e assim nos excluímos". Mello Leitão considerava a condenação da imigração japonesa como um impedimento a uma fonte de progresso. (Atas e Trabalhos do Primeiro Congresso Brasileiro de Eugenia, 1929 , p.20). A discussão a respeito da miscigenação e, conseqüentemente, da imigração, continua no outro dia de reunião e acaba esbarrando em outro aspecto bastante em pauta na eugenia brasileira: o mito do branqueamento. Na ocasião, Xavier de Oliveira apresentou seu trabalho intitulado "Da imigração européia para o nordeste brasileiro". N ele, O liveira falava da inferioridade física do nordestino e da melhora ocorrida quando este se misturava a raças superiores, como a alemã, por exemplo. Ele relatou o caso de duas irmãs cearenses ("fortes, robustas"), que quase tiveram sua descendência extinta, exceto por uma das bisnetas, que havia 
se casado com um alemão e gerado "duas crianças muito bem constituídas". Além disso, O liveira considerava os mulatos de uma inferioridade "apavorante". Roquette-Pinto ponderava alegando que O liveira havia chegado a tal conclusão a respeito dos mulatos após examinar pessoas doentes. A reprodução dessa passagem do congresso vem ilustrar os diferentes elementos do caleidoscópio eugênico que havia no Brasil. Até mesmo a miscigenação era vista de diferentes maneiras.

Dessa forma, o mito do branqueamento do país surge como algo regenerador de uma sociedade multirracial. A mistura de raças permitiria 0 branqueamento progressivo da população por meios naturais. 0 desaparecimento dos negros e índios puros era visto com certo otimismo. A imigração branca era saudada como um dos instrumentos mais eficazes para o branqueamento da população, visto que o seu cruzamento com os mulatos, por exemplo, acabaria por extinguir qualquer traço africano ou indígena que fosse. Ao menos no tom da pele. Tais populações eram segregadas não apenas racial, mas socialmente, vivendo em condições de extrema pobreza, marginalidade e repressão. Numa sociedade multirracial, buscava-se um denominador comum, mas dominado pela "branquidade" (STEPAN, 2004). Em linhas gerais, a fórmula para o branqueamento poderia ser representada como: miscigenação + altas taxas de mortalidade dos negros (SKIDM O RE, 1998).

\section{Eugenia na década de 1930: novo cenário, discussões e atores familiares}

A década de 1930 foi marcada por mudanças na política e na sociedade. Conforme Sousa (2000, p.221), a década de 1930 "representa um marco na trajetória da política social brasileira, uma vez que a 'questão social' passa a receber um tratamento 'bastante diferenciado' " se comparado ao período anterior, a República Velha. No governo Vargas essa área 
seria classificada como de "interesse prioritário". As interpretações acerca dos motivos que teriam levado o presidente a investir nessa área são diversas. Entretanto, essa mesma autora, ao abordar o problema do trabalho ilegal dos menores, alega que somente nesse período é que o poder público se posicionaria a respeito. 0 Estado, ainda segundo Sousa, se interessava em "propiciar melhores condições de vida e de trabalho ao operariado através de uma bem cuidada legislação social", como uma maneira de legitimar-se diante de um "novo quadro institucional que se inaugurava" (SO USA, 2000, p.239). Ao mesmo tempo, autores como Paiva (2003; 2006) apontam que após a Revolução de 1930, começa uma progressiva burocratização na saúde pública, o que acabaria dificultando o diálogo, a negociação entre o governo e figuras ativas como Belisário Penna ou Renato Kehl, por exemplo. A atenção dada a assuntos como família, maternidade, proteção à infância, melhores condições de trabalho à emergente classe operária já era prevista desde o início da Revolução de 30. Para Vargas, saúde e educação seriam os alicerces de um "Estado Nacional forte, unido e coeso". O presidente defendia esses atributos como alavancas do progresso econômico e social: "Para crescer e desenvolver-se, o Estado precisava compor-se de cidadãos selecionados por meio de processos eugênicos, saudáveis física e mentalmente, e para tanto impunha-se a tarefa de proteger e assistir a maternidade, a infância e a juventude" (SO USA, 2000, p.247). Nos Boletins de Eugenia editados por Renato Kehl, entre os anos de 1929 a 1931, é possível verificar a convergência entre as preocupações dos eugenistas e as do Estado. Entre os vários artigos, algumas traduções, é comum encontrar textos relacionados à concepção consciente, mortalidade infantil, exames pré-nupciais, puericultura, saúde, higiene, educação sexual. Não é por menos que os eugenistas viam no novo governo uma oportunidade para consolidar algumas de suas aspirações nacionalmente.

Em 1931, Renato Kehl, o mesmo que havia fundado a Sociedade Eugênica de São Paulo, em 1918, organizaria a Comissão Central Brasilei- 
ra de Eugenia, no Rio de Janeiro. A Comissão tinha como objetivos principais intensificar o estudo e a propaganda da eugenia no país. Além de ser um pólo de convergência e de difusão de idéias, ensinamentos. Segundo o próprio Kehl, a comissão trabalharia de acordo com o "interesse e espírito nacionais". As propostas resumiam-se a três aspectos: a) manter o interesse pelo estudo das questões relacionadas à hereditariedade e à eugenia; b) lutar pela irradiação dos ideais de regeneração tanto física, psíquica, como moral e c) "prestigiar ou mesmo auxiliar os empreendimentos científicos ou humanitários de caráter eugênico e dignos de apreço" (Kehl, 1931, p.1). O rganizada num período de experimentação política, de aspiração a uma nova constituição a ser promulgada em 1934, a comissão se prontificava

a colaborar com qualquer projeto governamental que visasse interesses eugênicos ou para-eugênicos, como sejam ligados à imigração, ao povoamento, ao saneamento, à educação sexual, às exigências modernas prématrimoniais, à fundação de estabelecimentos ou laboratórios para estudos galtonianos (KEHL, 1931, p.1).

Cargos ocupados por alguns membros como Belisário Penna - diretor geral do Departamento Nacional de Saúde Pública, Achiles Lisboa higienista e eugenista, Ernani Lopes - Presidente da Liga Brasileira de Higiene Mental e Gustavo Lessa - assistente do Departamento Nacional de Saúde Pública, por exemplo, indicam a proximidade que os eugenistas acreditavam ter com o governo federal. A projeção política de Belisário Penna, já vinha se consolidando desde as campanhas sanitárias empreendidas na década de 1920. Por essa constituição ainda e pela repetição de nomes que já haviam composto outras organizações eugênicas é possível dizer que os assuntos a serem debatidos no novo governo seriam basicamente os mesmos da década anterior.

Isso não significa que o movimento eugenista brasileiro ficou engessado por teorias seja de Lamarck, M endel ou outros. A própria trajetória de Rena- 
to Kehl ilustra a movimentação da eugenia no país. Segundo Castañeda (1998), por meio de uma análise feita de três, das diversas obras de Kehl, é possível observar essa movimentação. 0 livro Eugenia e medicina social, de 1920, é lançado no contexto da campanha sanitária, que tinha como meta livrar o Brasil de males que tornavam a população doente e não degenerada, como acreditavam alguns. Nessa obra, Kehl equivalia eugenia ao sanitarismo, enfatizando medidasligadas a uma eugenia preventiva. Na obra Lições de eugenia, de 1929, além da eugenia preventiva, o eugenista também passava a considerar as eugenias positivas e negativas. A primeira estimularia os "matrimônios eugênicos", com uma prole consideravelmente grande, como meio de equilibrar a proliferação daqueles considerados inaptos. A eugenia negativa, por sua vez, defendia os exames pré-nupciais, a proibição dos casamentos daqueles que poderiam gerar descendentes inadequados e a esterilização dos degenerados e criminosos. Ao mesmo tempo, Kehl estabeleceria uma divisão entre eugenia e eugenismo. A eugenia, segundo ele, seria a ciência, aquela que investigaria, escolheria e coordenaria os fatos. Enquanto isso, eugenismo seria sua aplicação na sociedade. Já no livro Aparas eugênicas: sexo e civilização, de 1933, a idéia de higiene da raça é separada da higiene sanitária. Nesse momento, a higiene da raça passava a se ligar, especificamente, à higiene das células reprodutoras. Essa oscilação, ainda segundo CASTAÑEDA, demonstra o amadurecimento de Kehl em relação às teorias da época (CASTAÑEDA, 1998, p.259-271). Dadas essas movimentações, essa mesma autora diz que a eugenia no Brasil, e de maneira geral, se desenrolou num terreno movediço.

Já nas primeiras iniciativas do Governo Provisório, instituído logo após a Revolução, Vargas manifestava sua preocupação com a saúde e a proteção à infância, assuntos já bastante discutidos pelos eugenistas desde a década de 1920. Para ele, essas questões se ligavam diretamente ao crescimento do país, bem como ao aperfeiçoamento da raça. 0 desafio era exorcizar o grande fantasma da mortalidade infantil. 0 período Vargas vai ao encontro das aspirações dos eugenistas ao fixar como objetivo a cons- 
trução de "uma nação composta de 'cidadãos fortes e capazes". Isso seria assumido pelo Poder Público com a cooperação da iniciativa privada. Para concretização desse projeto nacionalista tornava-se necessário "zelar pela saúde", pelo "desenvolvimento físico e mental das gerações futuras". Para tanto, realizou-se em 1933, a Conferência Nacional de Proteção à Infância, no qual se discutiu medidas ligadas às questões da saúde e do bemestar tanto das crianças como também das mães; desenvolvimento e educação infantil (desde o nascimento até a adolescência) e à assistência à maternidade. 0 s debates resultaram na criação da Diretoria de Proteção à M aternidade e à Infância, subordinado ao M inistério da Educação e Saúde Pública, no lugar da Inspetoria de H igiene Infantil (SO USA, 2000, p.223).

A questão da imigração continuaria a ser uma constante no governo Vargas. O s debates acerca de quem poderia ou não entrar no país sempre permearam as preocupações dos eugenistas. Artigos publicados no Boletim de Eugenia, de novembro de 1929, ilustram a mesma força heterogênea que compôs o governo Vargas e a posição dos eugenistas em relação à imigração. No artigo intitulado "O problema imigratório e o futuro do Brasil", é possível identificar a apologia em relação à imigração européia: “Todo o nosso esforço em política imigratória deve tender para incentivar ao afluxo do sangue europeu, e deste em especial dos povos que maiores afinidades de raça conosco tiverem". Para se colocar contra a imigração japonesa, o artigo relata a defesa da Argentina em relação aos nipônicos, exalta as qualidades de tal raça, mas frisa que esse povo, tão "diferente" do Brasil, não poderia ser bem-vindo. Os serviços de imigração, como alojamento na hospedaria e procura de trabalho se restringiria apenas aos imigrantes europeus (TELLES, 1929, p.3).

\section{Considerações finais}

A eugenia brasileira nas duas primeiras décadas do século XX possuía características particulares, distintas daquela praticada nos Estados U nidos 
e na Alemanha. Em primeiro lugar sua inclinação neolamarckiana e a crença de que as condições do meio ambiente incidiriam diretamente na constituição do povo brasileiro. Segundo: a busca por soluções que atendessem às peculiaridades do país e não simplesmente reproduzissem o que os eugenistas estrangeiros acreditavam. Terceiro: a defesa de um ideal de regeneração de uma raça, ao contrário da tese de degeneração defendida em outros países.

O que este trabalho tentou fazer foi debruçar-se sobre um período no qual a eugenia começava a se institucionalizar no Brasil, contando com nomes já consagrados na classe médica como Belisário Penna, Renato Kehl e outras figuras eminentes na discussão acerca da constituição da raça brasileira como o antropólogo e então diretor do M useu Nacional, Edgar RoquettePinto, e figuras que começariam a despontar nessa discussão, como o professor do Departamento de Zootecnia da Escola Agrícola Luiz de Queiroz (Esalq - Piracicaba), O ctávio Domingues. Nesse período, até a segunda década do século XX, a eugenia no Brasil era sinônimo de saneamento. As expedições dos médicos Belisário Penna e Artur Neiva haviam desnudado as condições precárias, insalubres e desumanas nas quais os sertanejos viviam. Mais que isso: derrubavam a visão romântica de alguns a respeito do sertão brasileiro. Por outro lado, essa constatação propiciaria um alívio para aqueles que julgavam o povo brasileiro condenado pela raça e pelo clima.

O bservamos que o período no qual a eugenia começa a se institucionalizar no país, com a criação da Sociedade Eugênica de São Paulo, em 1918, coincide com a chegada da Fundação Rockefeller ao país. No período compreendido entre 1910 a 1920, a fundação norteamericana desempenha papel fundamental na implementação de programas de saúde pública, como o combate à ancilostomíase, à febre amarela, e a assuntos que se relacionavam ao saneamento. Num primeiro momento, pode-se falar que a Fundação Rockefeller participou do movimento 
eugenista brasileiro, por uma via alternativa, por meio do movimento sanitarista. Algumas das figuras que trabalharam diretamente tanto nas negociações da Rockefeller com as autoridades brasileiras, bem como na implementação efetiva da ação dela no país, se destacaram também na eugenia brasileira. É o caso do médico Arnaldo Vieira de Carvalho, figura chave na parceria estabelecida entre a Fundação Rockefeller e a U niversidade de São Paulo (USP), na criação da Faculdade de Medicina. Além de diretor clínico da Santa Casa de Misericórdia e do Instituto Vacinogênico, Carvalho era também presidente da Sociedade Eugênica de São Paulo.

Diferentemente da maneira como a Fundação financiou programas ligados diretamente à eugenia como nos Estados U nidos e na Alemanha, no Brasil, a Rockefeller se viu envolvida num movimento que já vinha se consolidando no país. Contrapondo-se à degeneração das raças, aqui se buscava a regeneração de um povo doente. A preocupação com o controle dos corpos que permeava o movimento como um todo, aqui se estendia também para o meio ambiente no qual esses corpos viviam e conviviam. Defendia-se também o controle dos casamentos, os exames-prénupciais, mas acreditava-se que somente por meio do saneamento, se daria efetivamente o melhoramento do brasileiro.

Isso nos leva a defender que mais do que uma participação indireta, a Fundação Rockefeller se viu enredada por uma rede de atores já estabelecida no país, que atuava fortemente tanto no movimento sanitarista, bem como na eugenia. 0 que se estabeleceu entre a Fundação Rockefeller e o Brasil pode ser classificado como um acordo de cooperação internacional, ou seja, uma troca de saberes entre os financiadores e os receptores da doação. N ormalmente, esse tipo de acordo se efetiva por meio de ações que fomentam as atividades científicas de maneira continuada, incluindo quase sempre algum tipo de financiamento. Dessa maneira, é possível averiguar que as ações da Fundação Rockefeller, naquilo que 
se refere à eugenia, na Alemanha, ou ao sanitarismo/eugenia no Brasil, não eram ações isoladas, mas parte de uma política de cooperação internacional. Novamente, ao contrário, do que alguns autores querem nos levar a crer, não foi um ato isolado, mas sim uma política de incentivo à ciência em escala mundial.

\section{Eugenics and the Rockefeller Foundation in Brazil: health as an instrument of national regeneration}

\section{Abstract}

In the first decades of the twentieth century, the work of the Rockefeller Foundation was decisive for the implementation of public health initiatives in Brazil, especially in the so-called public health movement. At that time, Brazilian eugenics was the same as public health, as expressed in the maxim "to sanitize is to eugenize". There are several studies discussing the public health movement, the issue of public health in Brazil, the Rockefeller Foundation, eugenics and its supporters. However, there is little discussion on the relationship between the Rockefeller Foundation and the Brazilian eugenics movement. It is worth to mention that although there are issues related to race, and theories on genetics and evolution, this work does not intend to examine these issues in depth. The aim was to recreate the scenario in which eugenics in general, and particularly in the Brazilian case, was developed, exposing the positions of some of the Brazilian eugenicists.

Keywords: Eugenics. Public health. Rockefeller Foundation. International cooperation.

\section{Referências}

BLACK, Edwin. A guerra contra os fracos: a eugenia e a campanha norte-americana para criar uma raça superior. Tradução Tuca M agalhães.São Paulo: A Girafa Editora, 2003. 856 p. 
CAM PO S, Cristina. São Paulo pela lente da higiene. As propostas de Geraldo de Paula Souza para a cidade (1925-1945). São Carlos: RiMa Editora, 2002. 157 p. CAND EIAS, Nelly. Memória histórica da Faculdade de Saúde Pública da Universidade de São Paulo (1918/1954). Revista de Saúde Pública, São Paulo, v. 18, n. especial, 1984. p. 2-60.

CASTAÑEDA, Luzia Aurélia. Apontamentos historiográficos sobre a fundamentação biológica da eugenia. Episteme, Porto Alegre, n. 5, 1998. p. 23-48.

. Eugenia e casamento. História Ciência Saúde - Manguinhos, Rio de Janeiro, v. 10, n. 3, set./dez., 2003. p. 901-930.

CASTRO SANTOS, Luiz. A. de O pensamento sanitarista na Primeira República: uma ideologia de construção da nacionalidade. Dados. Revista de Ciências Sociais, Rio de Janeiro, v. 28, n. 2, 1985. p. 193-210.

. A Fundação Rockefeller e o Estado Nacional (história e política de uma missão médica e sanitária no Brasil). Revista Brasileira de Estudos da População, São Paulo, v. 6, n. 1, 1989. p. 105-110.

. Poder, ideologias e saúde no Brasil da Primeira República: ensaio de sociologia histórica. In: HOCH M AN, Gilberto; ARM US, Diego (O rg.) Cuidar, controlar, curar: ensaios históricos sobre saúde e doença na América Latina e Caribe. Rio de Janeiro: Fiocruz, 2004. 567. p. p. 249-293.

CASTRO SANTOS, Luiz. A.; FARIA, Lina. A reforma sanitária no Brasil: ecos da Primeira República. Bragança Paulista: ED USF, 2003. 204 p.

CUETO, Marcos. Los ciclos de la erradicación: la Fundación Rockefeller y la salud pública latinoamericana, 1918 - 1940. in CUETO, M. (ed.), Salud, cultura y sociedad em América Latina. Lima: IEP/O PS, 1996. p. 179-201.

D O M IN GU ES, O ctávio. 0 meio revela.... Boletim de Eugenia, Rio de Janeiro, ano II, n. 16, 1930.

Eugenia - seus propósitos, suas bases, seus meios. São Paulo: Companhia Éditora Nacional, 1933. 148 p.

FARIA, Lina. Arquivo Rockefeller. História, Ciências, Saúde - Manguinhos, Rio de Janeiro, v. 1 n. 2, nov 1994 - fev. 1995. p. 117-128.

- O Instituto de Higiene: contribuição à história da ciência e da administração em saúde em São Paulo. Physis, Rio de Janeiro, v. 9, n. 1, 1999. p. 175-208.

. Saúde e política. A Fundação Rockefeller e seus parceiros em São Paulo. Rìo de Janeiro: Fiocruz, 2007. 208 p.

KEHL; Renato. Eugenia e Medicina Social - problemas da vida. Rio de Janeiro: Livraria Francisco Alves, , 1923. 2ª ed 247 p. 
. Lições de eugenia. Rio de Janeiro: Livraria Francisco Alves, 1929. 313 p. . U ma nova entidade científica que aparece: a Comissão Central Brasileira de Eugenia. Boletim de Eugenia, Rio de Janeiro, n. 27, ano III, 1931. p. 1-2.

KOBAYASHI, Elizabete Mayumy. Eugenia e Fundação Rockefeller no Brasil: a saúde como instrumento de regeneração nacional. 2007, 103 f. Dissertação (M estrado em Política Científica e Tecnológica) - Departamento de Política Científica e Tecnológica, Instituto de Geociências, Universidade Estadual de Campinas, U nicamp, São Paulo.

LIM A, Nísia. T. ; HO CHM AN, Gilberto. Condenado pela raça, absolvido pela medicina: o Brasil descoberto pelo movimento sanitarista da Primeira República. In: M AIO, Marcos Chor; SANTOS, Ricardo Ventura (O rgs.). Raça, ciência e sociedade. Rio de Janeiro: Fiocruz, Centro Cultural Banco do Brasil, 1996. 252 p. p. 20-35.

M ACKENZIE, Donald Eugenics in Britain. Social Studies of Science, n.6, , 1976. p. 499-532. Disponível em: http://sss.sagepub.com/content/vol6/issue3-4/. Acesso em: 26 mar 2006.

M ARINH O, Maria. Gabriela Norte-americanos no Brasil: uma história da Fundação Rockefeller na Universidade de São Paulo (1934-1952). Campinas: Autores Associados, São Paulo: Universidade São Francisco, 2001. 214 p.

PAIVA, Carlos Henrique A. A saúde pública em tempos de burocratização: o caso do médico Noel Nutels. História, Ciências, Saúde - Manguinhos, Rio de Janeiro, v. 10, n. 3, set./dez. 2003. p. 827-851,

. Samuel Pessoa: uma trajetória científica no contexto do sanitarismo campanhista e desenvolvimentista no Brasil. História, Ciências, Saúde - Manguinhos, Rio de Janeiro, v. 13, n. 4, out./dez. 2006. p. 794-831.

PALM ER, Steven. Saúde imperial e educação popular: a Fundação Rockefeller na Costa Rica em uma perspectiva centro-americana, 1914-1921. In: HOCHMAN, Gilberto ; ARMUS, Diego, Cuidar, controlar, cuidar: ensaios históricos sobre saúde e doença na América Latina e Caribe. Rio de Janeiro: Editora Fiocruz, 2004. (Coleção História e Saúde)

REIS, José Roberto Franco Higiene Mental e eugenia: o projeto de 'regeneração nacional' da Liga Brasileira de Higiene Mental (1920-1930). 1994. 353 f. Dissertação (de mestrado) - Instituto de Filosofia e Ciências Humanas, IFCH, Universidade Estadual de Campinas, Unicamp, São Paulo.

RO Q UETTE-PIN TO, Edgar Ensaios de Anthropologia Brasiliana. São Paulo: Companhia Editora Nacional, 1933. 190 p.

SO U SA, Cynthia. Pereira de. Saúde, educação e trabalho de crianças e jovens: a 
política social de Getúlio Vargas. In: GO M ES, Angêla de Castro (O rg.). Capanema: o ministro e seu ministério. Rio de Janeiro: Editora FGV; Bragança Paulista: U niversidade São Francisco, 2000. 269 p. p. 221-249.

SO UZA, Vanderlei Sebastião de. A política biológica como projeto: a "Eugenia Negativa" e a construção da nacionalidade na trajetória de Renato Kehl (19171932). 2006, 220 f. Dissertação (M estrado em História das Ciências da Saúde) Casa de O swaldo Cruz - Fiocruz, Rio de Janeiro.

STEPAN, Nancy L. The Hour of eugenics: race, gender and nation in Latin America. New York: Cornell U niversity Press, 1991. 248 p.

. Eugenia no Brasil, 1917 - 1940. In: HOCHMAN, G.; ARMUS, D. (Orgs.) Cuidar, controlar, curar: ensaios históricos sobre saúde e doença na América Latina e Caribe. Rio de Janeiro: Fiocruz, 2004. 567 p. p. 331-391.

SKID M O RE, Thomas E. U ma história do Brasil. São Paulo: Paz e Terra, 1998. 254 p. TELLES, Antonio de Q ueiroz. O problema imigratório e o futuro do Brasil. Boletim de Eugenia Rio de Janeiro, n.11, 1929. p. 3-4.

WELLS, Hebert George; HUXLEY, Julian.; WELLS, George Philip. A ciência da vida: evolução dos seres vivos. Rio de Janeiro: Livraria José O lympio Editora. Tradução: Almir Andrade. v.3, 1941. 189 p.

Recebido: 30/01/2008

Aceite final: 23/09/2008 